\title{
Residências unipessoais e decisões de compra: caso do mobiliário
} Single person households and purchase decisions: furniture's case

Mariana Hahnemann Gonzaga1; Elton Moura Nickel² 


\section{Resumo}

Durante séculos a sociedade vem se modificando e, junto com ela, a maneira como as pessoas se comportam em relação às suas moradias. Esse trabalho trata de uma análise comportamental das residências unipessoais e das pessoas que ali habitam e como isso afeta suas decisões de compra de bens de consumo. Para a pesquisa foi feita um estudo de caso com 5 pessoas que são solteiras e moram sozinhas para comparar com outra pesquisa já realizada pelo Instituto Market Analysis e verificar se a tendência apontada pelo Instituto é concreta. Ao final do estudo foi verificado que, de maneira geral, as tendências apontadas pela pesquisa do Instituto são compatíveis com os estudos de caso, mas todos possuem suas particularidades. Essa característica deve ser observada pelo mercado de nicho que visa conquistar esse público alvo, conforme ilustrado pelo mobiliário projetado em paralelo à pesquisa.

Palavras-chave: Moradia unipessoal, Público single, Comportamento, Bens de consumo.

\section{Abstract}

For centuries society has been changing and, with it, the way people behave in relation to their homes. This paper deals with a behavioral analysis of single person households and the people who live there and how it affects their purchase decisions of consumer goods. To research a case study with 5 people who are single and live alone to compare with other research already carried out by the Market Analysis Institute and verify if the trend indicated by the Institute is concrete was taken. At the end of the study it was found that in general, the trends shown by the research of the Institute are supported by case studies, but all have their peculiarities. This feature should be observed by the niche audience that seeks to conquer the market, as illustrated by the furniture designed in parallel to search.

Keywords: Sole residence, Single person, Behavior, Consumer goods. 


\section{Introdução}

O atual processo de desenvolvimento da sociedade e suas inúmeras mudanças trazem à tona um grupo em especial de consumidores: aqueles que moram sozinhos. Essa tendência foi observada inicialmente duas décadas atrás na Europa pelo aumento da expectativa de vida da população, a alteração da configuração da estrutura familiar, a verticalização urbana, independência financeira dos jovens, dentre outros fatores. Esse nicho de mercado consumidor, uma entidade compradora potencial, é o foco de muitas empresas e indústrias, considerando que a projeção das pesquisas é que esse nicho só venha a aumentar. Prever os movimentos demográficos significa sair à frente dos concorrentes.

Apesar de ser um publico alvo em pleno crescimento, existem muito poucas pesquisas sobre o mesmo. Observar as mudanças, detectar um nicho em potencial e investir nele pode trazer grandes vantagens para quem produz e para quem desfruta desses benefícios. São pesquisas que interessam não somente para os profissionais de marketing, mas para os ligados à indústria de consumo, bem como arquitetos, designers, engenheiros, administradores, farmacêuticos, dentre outros. Observar essas mudanças e tentar prevê-las pode ajudar a gerar diferenciais para determinado produto ou serviço que conquistem o cliente. Atualmente, com a alta oferta de produtos e serviços no mercado, ter a preferência por parte dos consumidores é essencial.

Nesse contexto, o presente artigo tem como objetivo apresentar uma análise comportamental, bem como o estilo de vida das pessoas que moram sozinhas. 0 trabalho foi feito com base na pesquisa bibliográfica e no método do estudo de caso, abordagens que serão apresentadas nos tópicos que se seguem.

\section{Revisão Bibliográfica}

Um nicho de mercado é classificado considerando pessoas que possuem traços similares e, segundo Kotler \& Armstrong (1998), eles podem ser hábitos de compra, preferências, poder de compra, localização geográfica ou atitudes de compra. Assim, podemos considerar as pessoas que moram sozinhas como um nicho (Single Household, Mono residência), pois elas possuem traços similares de ações e decisões, e pelo fato de viverem sozinhas, assumem um mesmo estilo de vida. Para Solomon (2002), os estilos de vida dos consumidores são como um alvo em movimento. Ainda, segundo o autor, "as prioridades e referências da sociedade estão constantemente evoluindo, e é essencial para os profissionais de marketing acompanhar essas mudanças e, o mais importante, tentar prevê-las." (SOLOMON, 2002, p. 156).

De acordo com os dados mais recentes do Censo 2010, os brasileiros que vivem sozinhos são cerca de 6,9 milhões. E pouco mais de $12 \%$ dos domicílios brasileiros são ocupados por apenas um morador; em 2000 eram 8,6\% (ESTADO DE MINAS, 2012). Dessa maneira podemos observar que se trata de um nicho de mercado significativo e que aumentou quase 4\% em 10 anos. Outras pesquisas mostram que no Brasil, a maioria dos moradores solitários continua sendo a população mais velha, ou seja, 40\% têm mais de 60 anos. Contudo, as faixas etárias mais jovens estão ga- 
nhando espaço, pois 11,4\% deles têm entre 20 e 29 anos e 13,2\%, entre 30 e 39 anos (JORDÃO \& LOES, 2012).

Barrucho (2012) ainda cita o contingente feminino, agora com maior inserção no mercado de trabalho e, consequentemente, mais independente. Cita-se também o aumento no número de divórcios e os jovens que saem de casa para morar sozinhos, devido à oportunidades de emprego, como perfis também presentes nas mono residências.

Vale ressaltar que a atual segmentação de mercado não exclui a cultura massificada, mas apenas põe em evidencia a cultura de nichos. "A cultura de massa não deixará de existir, ela simplesmente se tornará menos massificada. E cultura de nicho já não será tão obscura." (ANDERSON, 2006, p. 180). Anderson (2006) conclui que todos nós, por mais que nos julguemos enquadrados em algo denominado de 'tendência dominante', sempre nos encaixamos em supernichos, sob alguns aspectos da nossa vida.

Para Caldas (2004), a previsão de demanda é algo inerente ao ser humano, mas evidencia a dificuldade de que quanto mais complexa se torna a sociedade, mais difícil é prever o que os clientes estão procurando. Para o autor, "é imperativo que o homem especule sobre o que está por vir, pois fazer previsões é uma forma de controlar a vida e de confrontar a experiência da morte que trazemos no inconsciente." (CALDAS, 2004, p. 35). Por outro lado, ele alerta que quanto mais complexa se torna a sociedade, maior e mais difícil se torna a necessidade de planejá-la e prevê-la.

Caldas (2004) também evidencia que podemos fazer um estudo de comportamento de consumidores, observando diversas características diferentes, desde aspectos psicológicos, físicos, culturais, por meio de linguagem corporal, dentre tantos outros. Isso pode ser feito porque tais padrões identificados se repetem e de maneira inconsciente. No âmbito da psicologia, o estudo do comportamento dá-se por intermédio da identificação desses modelos que se repetem. "No entanto, por meio da analise da casa, do modo de decorar os interiores e o local de trabalho, observando a forma de dispor os moveis, a escolha de objetos, o uso das cores, etc., obtêm-se informações reveladoras sobre o comportamento individual." (CALDAS 2004 p. 99).

Schiffman \& Kanuk (2000), ao estudar o comportamento de compra dos consumidores, perceberam que apesar de existir uma abordagem de identificação e moda, muitos consumidores eram contra a utilização daquilo que a massa possuía. Pelo contrário, preferiam produtos diferenciados e que os mesmo pudessem refletir suas particularidades, peculiaridades e estilo de vida.

Portanto, a segmentação de mercado tem seus prós e contras. Assim, concluise que, de acordo com Weinstein (1995), os principais benefícios da análise e estratégias de segmentação de mercado são:

- Projetar produtos que atendam eficazmente as necessidades do mercado. Elaborar estratégias promocionais eficazes e de baixo custo;

- Avaliar a concorrência, especialmente a posição de mercado da empresa e promover insights junto às estratégias de marketing atuais. Bem como suas limitações: aumento de custos; 
- Mais comprometimento corporativo;

- Prover perfis genéricos e não individuais.

\section{Metodologia}

Após a revisão da literatura, para a presente pesquisa foram feitas cinco entrevistas (estudos de caso), de maneira onde se pudessem observar padrões das pessoas que moram sozinhas de maneira mais pontual, com o objetivo de identificar tendências e/ou padrões de comportamento desse nicho de mercado, confrontando a pesquisa já realizados pelo do Instituto Market Analysis, em 2008, onde foram entrevistadas 1.100 pessoas que moram sozinhas, distribuídas em 8 capitais brasileiras (CORDIOLI, 2011).

O grande diferencial do estudo de caso foi a possibilidade de observar se esses padrões de comportamento verificados pela pesquisa do Instituto seriam reprodutíveis também com pessoas escolhidas aleatoriamente. Também foi possível verificar de forma mais qualitativa os dados obtidos quantitativamente na pesquisa da Market Analysis, observando cada particularidade e/ou generalização dos indivíduos estudados.

Para o estudo de caso foi utilizado o método de Yin (2005), como segue na Figura 1.

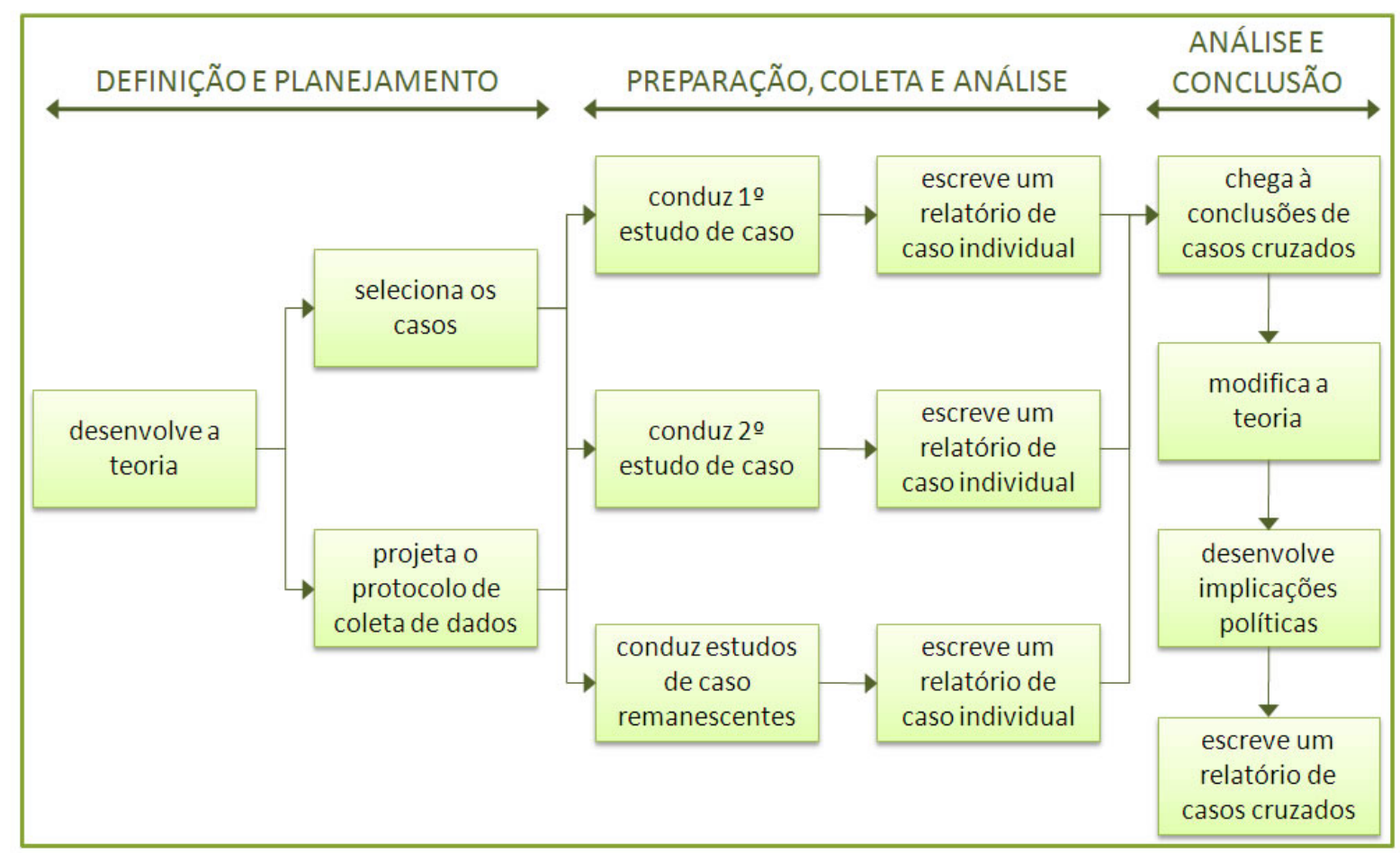

Inicialmente foi proposta a teoria de que nem todos os indivíduos que moram sozinhos se encaixam no padrão generalizado pela pesquisa do Instituto Market Analysis, justamente pelo fato de ser uma pesquisa quantitativa. Depois foram selecionados os cinco casos a serem estudados, de forma aleatória ou por sua disponibilidade. Foi planejado um roteiro para o protocolo do questionário a ser aplicado. $O$ 
roteiro continha perguntas relacionadas ao estilo de vida, moradia, estudo, trabalho, meios de transporte, dentre outros aspectos importantes. As perguntas foram feitas de modo a obter o máximo de informações possíveis sobre o público alvo, tentando desvendar suas particularidades. Após isso, os relatórios foram analisados entre si, verificando suas particularidades e/ou similaridades e depois foram comparados com os dados coletados pelo Instituto de Pesquisa Market Analysis. As pessoas entrevistadas para o estudo têm entre 21 a 28 anos, do sexo masculino e feminino e moram no mínimo há 4 anos sozinhos e, no máximo, 8 anos.

\section{Resultados do Estudo de Caso}

Os resultados da pesquisa foram organizados em tópicos, conforme seguem:

a) Estabilidade Financeira: Os casos 1 e 3 são ambos estudantes de medicina, não possuindo rendimento próprio e são sustentados por seus pais. Os casos 2, 4 e 5 são empregados, respectivamente como Engenheiro de produção, Sommelier de cerveja e Contador e são independentes financeiramente.

b) Morar sozinho: Em todos os casos, as pessoas entrevistadas moram sozinhas porque inicialmente saíram de casa para estudar em outras cidades. Os casos 2 e 5 , ao voltarem para suas cidades de origem, optaram por continuar morando sozinhos, pois estavam acostumados com sua independência e tinham condições financeiras para tal. Os casos 1 e 3 continuam morando fora de sua cidade de origem, sendo que apenas o caso 1 tem pretensão de voltar. Já o caso 4 se mudou para uma terceira cidade após a graduação.

c) Residências: Os casos 3 e 5 compraram seus apartamentos, pois pretendem morar ali definitivamente. Os casos 1, 2 e 4 têm seus apartamentos alugados, ou por razões financeiras ou pelo fato de não terem certeza se será sua moradia definitiva. Com esse pensamento de moradia definitiva, o caso 3 mobiliou seu apartamento com moveis sob medida bem como o caso 5 , que não escolheu moveis sob medida, mas móveis que se adequassem ao apartamento. De todas as residências apenas o caso 4 mora em um apartamento com apenas um quarto. Nos casos 1, 2 e 3 os apartamentos tem 2 quartos e o apartamento do caso 5 possui 3 quartos.

d) Alimentação: Todos os casos têm o costume de comer fora de casa, geralmente no horário do almoço, pois afirmam que pelo fato de morarem sozinhos e pela falta de tempo no dia a dia, voltar para casa e cozinhar para uma pessoa não é prático. As outras refeições podem ser feitas em casa, mas são classificadas como 'lanche'. Eles também afirmam que vão ao supermercado uma vez por semana, para comprar o básico.

e) Transporte: Com exceção do caso 4 que tem como bicicleta o meio principal de locomoção, todos os outros casos utilizam-se de carro como principal meio de locomoção pela comodidade e conforto que lhes oferece. Mesmo se houvessem transportes públicos de qualidade eles não abririam mão de andar de carro. 
f) Lazer: Como atividades de lazer, os casos 2 e 3 responderam que seus principais momentos de lazer são quando estão praticando algum esporte. O caso 2 incluiu atividades físicas, Jiu Jitso e Wake Board e, o caso 3 musculação, corrida ou Surf. Os casos 1, 4 e 5 disseram não praticar atividades físicas, ou por falta de tempo ou de interesse/disposição. O caso 1 considera sair às compras uma atividade de lazer, pois disse que é o único momento que se desliga das atividades do curso de medicina. $O$ caso 4 disse que para ele atividade de lazer é a leitura e que coleciona livros. Já para o caso 5 sua principal atividade de lazer é ver filmes, pois ele é formado em Cinema e mantém a paixão pelos filmes.

g) Acesso à Tecnologia: Todos os casos disseram possuir internet em casa e com exceção do caso 1, todos têm TV a cabo. Todos os casos também disseram possuir aparelhos celulares do tipo Smartphone com acesso à internet.

h) Bens de consumo duráveis: Ao serem perguntados sobre seus objetos e o que eles sentiam sobre os mesmo, todos, exceto o caso 1, consideraram os seus objetos coisas efêmeras, passageiras. Apesar disso, o caso 2 foi o único que disse não sentir apego aos seus objetos nem tomar cuidado com os mesmos. Sobre bens de consumo duráveis que eles não possuem e que gostariam de comprar, o caso 1 gostaria de uma televisão nova, o caso 3 um videogame novo e o caso 4 uma máquina de fazer sucos naturais, se no caso tivessem dinheiro para fazê-lo, pois consideram coisas 'supérfluas' e não de necessidade primordial. Sobre os objetos que eles dizem ser inúteis ou desnecessários, o caso 1 disse ter um aparelho de DVD que dificilmente usa, o caso 3 uma batedeira, que nunca usou e o caso 4 um ferro de passar roupa que não usa.

\section{Discussão dos Resultados do Estudo de Caso}

Para a discussão dos resultados foram levados em conta os dados obtidos pelo estudo de caso, em comparação com os dados do Instituto Market Analysis. A Tabela 1 abaixo serve como demonstrativo de resposta das perguntas de forma generalizada.

\section{TABELA 1 - Compilação dos principais resultados a partir dos casos selecionados.}

\begin{tabular}{|l|l|l|l|l|l|l|}
\hline & $\begin{array}{l}\text { Mora sozi- } \\
\text { nho }\end{array}$ & $\begin{array}{l}\text { Tem empre- } \\
\text { go }\end{array}$ & $\begin{array}{l}\text { Apartamen- } \\
\text { to próprio }\end{array}$ & Come fora & Tem carro & $\begin{array}{l}\text { Acesso à } \\
\text { internet }\end{array}$ \\
\hline Caso 1 & Sim & Não & Não & Sim & Sim & Sim \\
\hline Caso 2 & Sim & Sim & Não & Sim & Sim & Sim \\
\hline Caso 3 & Sim & Não & Sim & Sim & Sim & Sim \\
\hline Caso 4 & Sim & Sim & Não & Sim & Não & Sim \\
\hline Caso 5 & Sim & Sim & Sim & Sim & Sim & Sim \\
\hline
\end{tabular}

Fonte: Dos autores. 
A discussão dos resultados da pesquisa foi organizada com base nos tópicos já apresentados, conforme seguem:

a) Estabilidade Financeira: A pesquisa do Instituto apontou que as pessoas que moram sozinhas tem de 3 a 4 vezes mais chances de serem aposentados, profissionais liberais ou donos do próprio negócio e, consequentemente, que a renda desses lares chegue a ser 4,5 vezes maior do que nos lares com mais de duas pessoas. Em contrapartida, em nenhum dos 5 casos estudados, existe alguém com esse perfil (aposentado, profissional liberal, ou dono do próprio negócio). Os casos 1 e 3, estudantes de medicina, são totalmente mantidos financeiramente pelos pais, pois a carga horária e o currículo do curso não permitem emprego/estágio paralelo. Apenas o caso 5, que é contador e trabalha na empresa da família, recebe um pró-labore, pelo fato de ser sócio da mesma. O caso 2 é engenheiro contratado de uma consultoria de projetos internacional e o caso 4 é gerente de um bar de cervejas artesanais.

b) Morar sozinho: Os casos 2 e 5, que após terem saído de casa para estudar e retornaram para suas cidades de origem; e o caso 4 que se mudou para uma terceira cidade após a graduação reafirmam a teoria da inserção dos jovens no mercado de trabalho, já que logo após o término de sua graduação eles já tinham empregos e renda própria, podendo se sustentar.

c) Residências: Todos os entrevistados moram sozinhos - requisito inicial para participação da pesquisa. Mas, de acordo com a pesquisa bibliográfica, existe uma tendência que essas pessoas que moram sozinhas, morem em espaços pequenos. Isso vai contra a teoria de que a maioria das pessoas que mora sozinha mora exclusivamente em locais pequenos, como identificado nessa pesquisa. Apenas um dos casos estudados mora em um apartamento com um quarto. Isso pode ser relacionado com o alto poder aquisitivo dos entrevistados e também com o conforto que eles procuram. Apesar de apenas o caso 5 morar na cidade de São Paulo, ele é um exemplo que vai contra essa tendência, já que de todos os casos entrevistados ele é o único que mora em um apartamento de 3 quartos. Mesmo assim, paralelamente ao crescimento desse nicho de mercado consumidor, observa-se que os construtores tem se preparado para esse novo grupo de consumidores em expansão, visando sempre a construção de apartamento pequenos, lofts, kitinets, principalmente em cidades grandes como Rio de Janeiro e São Paulo, onde o custo de vida é muito alto. $O$ tamanho dos apartamentos, diretamente ligado ao seu valor e custo de manutenção não é a única razão pela escolha do mesmo. Como a casa é um ambiente sinônimo de conforto e relaxamento, atualmente as pessoas optam por um estilo de vida mais simples, justamente por que seu dia a dia já é estressante.

d) Alimentação: Todos os casos tem o costume de comer fora de casa, geralmente no horário do almoço, pois afirmam que pelo fato de morarem sozinhos e pela falta de tempo no dia a dia, voltar para casa e cozinhar para uma pessoa não é prático. Isso confirma os dados da pesquisa do Instituto Market Analysis, de que os 'singles' costumam ir mais a bares e restaurantes que a média da população ( $42 \%$ contra $21 \%$ ) 
e também fazem refeições em fast foods com frequência (36\%). As outras refeições podem ser feitas em casa, mas são classificadas como 'lanche'. Eles também afirmam que vão ao supermercado uma vez por semana, para comprar o básico. Sobre alimentação saudável apenas os casos 2 e 3 se disseram preocupados com sua alimentação, o que vai contra a pesquisa do Instituto de que a alimentação de quem mora sozinho é regida por produtos considerados saudáveis (64\% dos 'singles' versus $55 \%$ população geral). Em função desse estilo de alimentação saudável que os 'singles' teriam, a tendência seria comprar salgadinhos, snacks com menor frequência e beber menos refrigerante que o resto da população. Com o estudo de caso foi observado que apesar de terem o costume de ter refrigerante em casa, mas bebê-lo fora de casa, os casos 1, 4 e 5 dizem comer salgadinhos/snacks/doces mais do que eles mesmos consideram saudável para uma pessoa. Eles atribuem esse hábito às facilidades que esse tipo de alimento tem para ser consumido. Através das entrevistas, percebe-se que se concretiza o que aponta a pesquisa, que afirma que este grupo é responsável por $40 \%$ do consumo de produtos embalados individualmente, tendo também como preferência encontrar em um único local todos os produtos que procuram, pois os mesmos vão ao supermercado apenas uma vez por semana.

e) Transporte: Segundo o instituto de pesquisa Market Analysis, os moradores sozinhos tem mais noção de responsabilidade ambiental em relação ao resto da população (31\% versus $24 \%$ ) e são mais dispostos a adaptar seu estilo de vida para um modelo sustentável, mas dizem não se sentir ajudados pelas empresas para fazer escolhas mais responsáveis. O caso 4 é o único que se identifica como responsável ambientalmente, pois é o único que usa a bicicleta como meio de locomoção e, além disso, ele diz considerar a bicicleta também como um estilo de vida. Todos os outros casos possuem carro e o utilizam geralmente sozinhos. Aqui, a responsabilidade ambiental é referente aos transportes, exclusivamente, e não necessariamente a outros tipos de responsabilidade ambiental (economia de água, eletrodomésticos de baixo consumo de energia, reciclagem de resíduos sólidos, dentre outros).

f) Lazer: Segundo o instituto de pesquisa Market Analysis, a atividade de lazer mais citada por moradores sozinhos foi fazer compras (42\%). Dos entrevistados para este artigo, apenas o caso 1 considerou como sua principal atividade de lazer o ato de fazer compras. A pesquisa também indica que o tempo gasto com televisão é inferior ao tempo de uso da internet e que esse grupo utiliza em média 56 minutos diários, contra 34 minutos que o resto da população. $O$ caso 5 da pesquisa deste artigo reforça essa idéia, já que assiste filmes pela internet. As atividades de lazer, como identificado na pesquisa feita com os 5 moradores sozinhos e confrontada com a pesquisa da Market Analysis, giram em torno de 'compras', 'práticas de esportes' e 'cinema'. Perceptivelmente são práticas de exercício individual, o que fortalece a idéia de independência de quem opta por morar sozinho.

g) Acesso à Tecnologia: De acordo com os dados do IBGE, entre 2009 e 2011 os bens duráveis que apresentaram percentual mais elevado de crescimento foram o microcomputador com acesso à internet (39,6\%), seguido de microcomputador 
$(29,5 \%)$ e celular $(26,7 \%)$. Pode-se constatar pela pesquisa que todos os casos entrevistados possuem acesso à internet. De acordo com a pesquisa do Instituto Market Analisys, a maioria da população gasta cerca de 34 minutos por dia navegando, já aqueles que moram sozinhos cerca de 54. Esta é outra teoria comprovada pela pesquisa, principalmente porque todos os usuários possuem smarthphone com acesso à internet, deixando-os ainda mais conectados.

h) Bens de consumo duráveis: Esse público também é mais exigente em suas compras. A pesquisa do instituto revelou que os 'singles' são mais exigentes que a maioria da população, buscando preços mais em conta e pagam por produtos mais caros, desde que isso traga valores, como qualidade e durabilidade. No estudo de caso apareceram diferentes opiniões sobre os bens de consumo. A maioria considera-os coisas efêmeras, enquanto o caso 1 tem muito apego aos mesmos. Apesar disso, todos, menos o caso 2, disseram tomar cuidado com o que possuem. É o que diz Miller (2006), quando se refere aos cuidados que as pessoas dão aos objetos. Isso acontece porque, por sua vez, os objetos podem oferecer um retorno emocional aos cuidados que uma pessoa tenha thes oferecido. O retorno desses cuidados pode acontecer através de lembranças de momentos felizes e de como o mesmo fez parte da sua história.

Os resultados aqui obtidos e analisados confirmam a configuração de um perfil de público alvo específico, detentor de características que podem ser consideradas de modo padronizado para o desenvolvimento de novos produtos ou serviços. Os dados coletados, portanto, sugerem a possibilidade de generalização dos principais tópicos considerados no estudo de caso.

\section{Desdobramento da Pesquisa}

Essa pesquisa foi desenvolvida em paralelo com um Projeto de Graduação em Design Industrial, que proporcionou as diretrizes para a pesquisa do artigo em questão. Dessa maneira, os dois trabalhos foram feitos de forma colinear, resultando em um artigo cientifico e também seu desdobramento em um projeto de produto, voltado a ambientes monofamiliares (singlehouses).

Além das pesquisas aqui já descritas, também foi feito um levantamento histórico sobre a evolução das moradias, sobre seu significado social e, a partir disso, um questionário foi aplicado com pessoas que moram sozinhas - objeto de estudo em questão. Esse procedimento evidenciou a oportunidade para o projeto de graduação: um móvel pensado para pessoas que moram sozinhas e suas residências atuais - espaços reduzidos, como: lofts, kitnets e apartamentos pequenos. Esse móvel seria uma junção de mesa mais cadeira, móveis considerados como os mais importantes por essas pessoas que moram sozinhas. O mobiliário desenvolvido teria como diferencial sua multifuncionalidade, visando aumentar as possibilidades num espaço pequeno.

Para o desenvolvimento do projeto foram utilizadas as seguintes ferramentas: análise dos concorrentes, QFD, matriz morfológica e posicionamento de mercado. Dessa maneira foram definidos os atributos do projeto e as alternativas começaram a ser geradas. 
O conceito definido foi a versatilidade. A versatilidade se define como conceito nas múltiplas funções, no movimento, não do próprio objeto, mas na mudança a que ele pode se propor - ser uma mesa e cadeira, ou só cadeira. Ao tomar mais de uma forma, ele reforça o conceito de versatilidade, onde o móvel pode se adequar à situação. A geração de alternativas para o projeto pode ser observada na Figura 2.

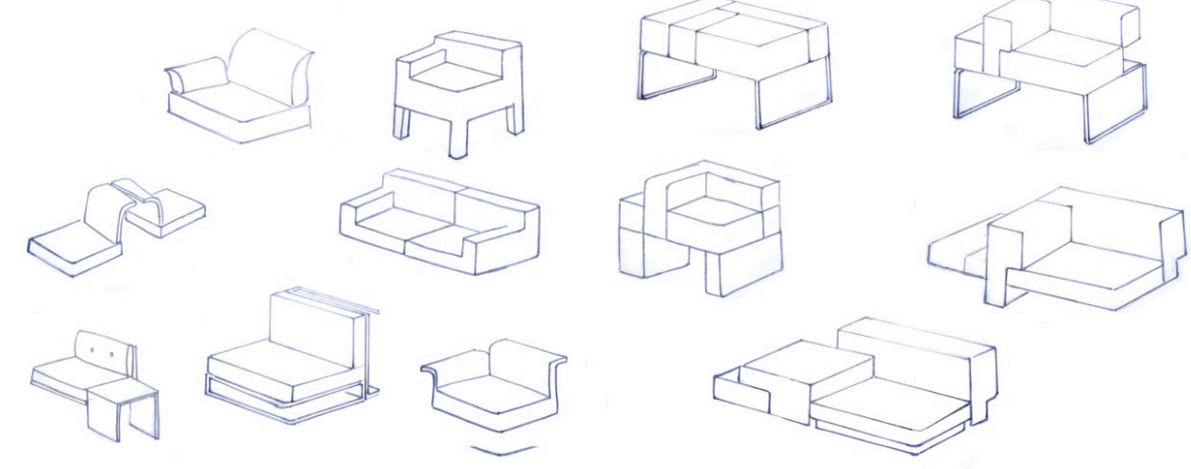

FIGURA 2 - Geração de alternativas (Fonte: do autor).

Após a geração, houve a definição da alternativa escolhida como melhor opção. Ela é composta de uma estrutura de aço e de 5 almofadas, que se encaixam criando duas possibilidades de sofá, conforme ilustrado na Figura 3.
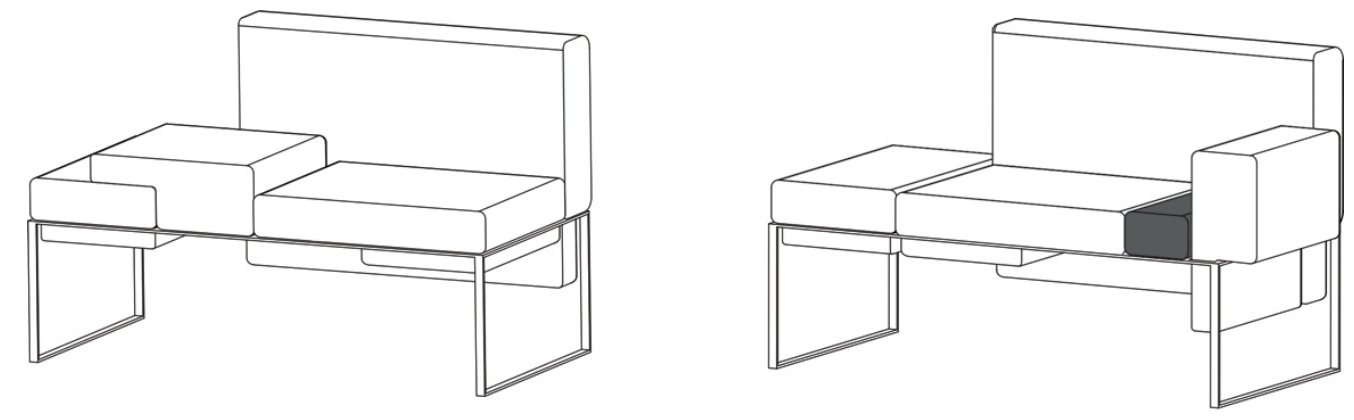

FIGURA 3 - Alternativa selecionada para o projeto (Fonte: do autor).

Para a apresentação do projeto de graduação foi feito um modelo em escala 1:5, após o que o projeto foi classificado como finalista na feira 'MovelSul', em Bento Gonçalves - RS, na edição de 2013. As medidas foram revistas com os orientadores do projeto e o mesmo foi executado em tamanho real e funcional para o envio à feira. Fotos do produto encontram-se na Figura 4.

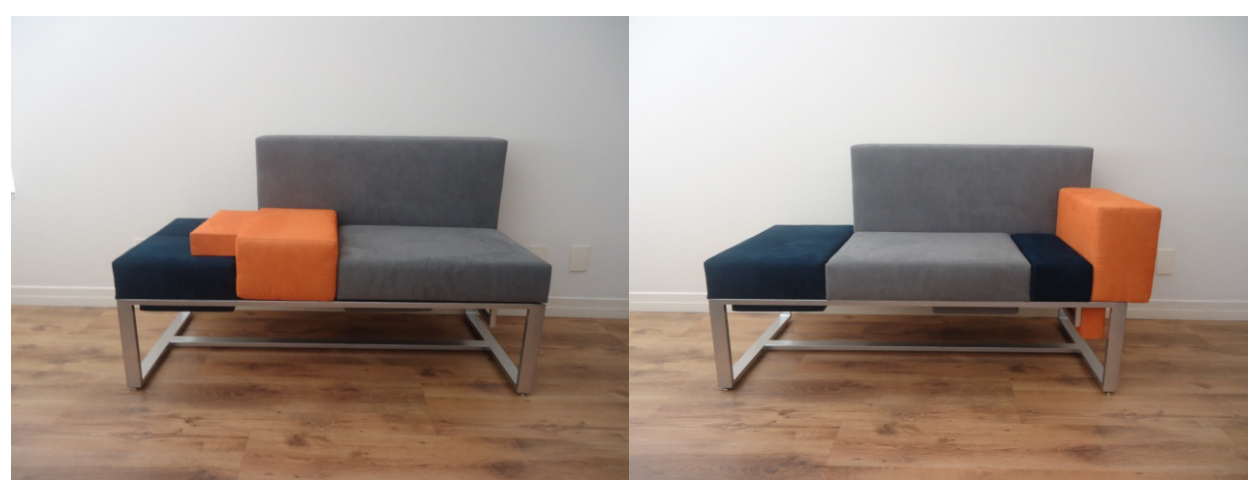

FIGURA 4 - Protótipo enviado à feira MovelSul (Fonte: do autor). 


\section{Considerações Finais}

O presente artigo apresentou uma breve descrição conceitual do mercado 'single', que diz respeito a pessoas que, por intenção ou necessidade, moram sozinhas. Foi visto que $o$ atual número de lares com apenas um morador tem uma tendência de crescimento no Brasil e no mundo. Esta situação tem como fatores o envelhecimento da população (aumento da perspectiva de vida), o aumento do número de divórcios e uma mudança no estilo de vida como um todo.

Considerando uma perspectiva mercadológica, foram realizadas entrevistas com um grupo de pessoas que moram sozinhas, primeiro de modo mais genérico e quantitativo, confrontando os dados com a pesquisa do Instituto Market Analysis, apresentados por Cordioli (2011). Num segundo momento, a pesquisa abordou um grupo de pessoas em particular, em forma de estudo de caso, o qual confirmou a tendência de alterar o mercado de massas para nichos paralelos.

Constatou-se, por fim, que o público analisado neste artigo tem necessidades específicas a serem consideradas nos mais diversos segmentos industriais. Sendo assim, torna-se evidente que esse grupo social específico, os 'singles', merecem a atenção do mercado global, pois podem representar importante fonte de renda, conforme ilustrado pelo produto desenvolvido e classificado para a feira de móveis sediada na região sul do Brasil. 


\section{Referências}

ANDERSON, C. A cauda longa. 5a Edição. Elsevier: Rio de janeiro, 2006.

BARRUCHO, L. G. Brasil desponta em número de 'solitários' entre emergentes. BBC Brasil, São Paulo. 2012. Disponível em: http://www.bbc.co.uk/portuguese/noticias/. Acesso em 09/05/2013.

CALDAS, D. Observatório de sinais. Senac Rio - Rio de janeiro, 2004.

COBRA, M. Marketing Basico: uma perspectiva brasileira. 1985 3ạ Edição, Atlas: São Paulo, 1985.

CORDIOLI, A. Em busca dos solteiros. Revista Varejo e oportunidades. Agosto, Setembro 2011. Pg. 16-18.

ESTADO DE MINAS. Brasileiros que moram sozinhos gastam mais, segundo pesquisa do IBGE. 2012. Disponível em: http://www.em.com.br/app/noticia/nacional/. Acesso em 09/05/2013

FORTY, A. Objetos de desejo: Design e sociedade desde 1750. São Paulo: Cosac Naify, 2007.

INSTITUTO BRASILEIRO DE GEOGRAFIA E ESTATÍSTICA - IBGE. PNAD 2011: crescimento da renda foi maior nas classes de rendimento mais baixas. Disponível em: http://saladeimprensa.ibge.gov.br/noticias. Acesso em 09/05/2013.

JORDÃO, C. \& LOES J. Eu quero ficar sozinho. Revista ISTOÉ, Comportamento. Edição 2085, Outubro 2009. Disponível em: http://www.terra.com.br/istoe-emp/edicoes/2085/imprime154639.htm Acesso em 09/05/2013.

KOTLER, P. \& ARMSTRONG, G. Princípios de marketing. 7a Edição. Prentice Hall: Rio de Janeiro, 1998.

MILLER, D. Things that bright up the place. Home Cultures, v. 3, n.3, p. 235-249. 2006. SAMARA, B. S. \& MORSCH, M. A. Comportamento do Consumidor. Pearson Prentice Hall - São Paulo, 2005.

SCHIFFMAN, L. G. \& KANUK, L. L. Comportamento do consumidor. 6a Edição.LTC Rio de Janeiro, 2000.

SOLOMON, M. R. Comportamento do consumidor: comprando, possuindo e sendo. 5a Edição. Bookman: São Paulo, 2006.

YIN, R. K. Estudo de caso: planejamento e métodos. 3ạ Edição. Bookman: São Paulo, 2005.

WEINSTEIN, Art. Segmentação de mercado. Atlas: São Paulo, 1995. 